\title{
EXTRAÇÃO DE NUTRIENTES PELA FITOMASSA DE CULTIVARES DE Brachiaria brizantha SOB DOSES DE NITROGÊNIO
}

\author{
Kátia Aparecida de Pinho Costa, ${ }^{1}$ Itamar Pereira de Oliveira, ${ }^{2}$ Eduardo da Costa Severiano, ${ }^{3}$ \\ Fabrício de Menezes Telo Sampaio, ${ }^{4}$ Murilo Sousa Carrijo ${ }^{5}$ e Carlos Ribeiro Rodrigues ${ }^{6}$ \\ 1. Professora, doutora, Universidade de Rio Verde. E-mail: katiazoo@hotmail.com \\ 2. Professor, doutor, Faculdade Montes Belos \\ 3. Bolsista de DCR (FAPEG/CNPq), Instituto Federal Goiano - Campus Rio Verde \\ 4. Professor, doutor, Universidade Federal do Piaú \\ 5. Professor, mestre, Universidade de Rio Verde \\ 6. Professor, doutor, Universidade Federal Rural do Pernambuco.
}

\section{RESUMO}

$\mathrm{O}$ fornecimento de nutrientes em quantidades adequadas e em proporções equilibradas é fundamental no processo produtivo das pastagens. Para o manejo da adubação, torna-se importante conhecer a necessidade de nutrientes das plantas forrageiras e, consequentemente, sua capacidade de extraí-los do solo. Diante disso, objetivou-se avaliar a extração de nutrientes pela fitomassa de cultivares de Brachiaria brizantha sob doses de nitrogênio. O delineamento experimental utilizado foi blocos completos ao acaso, com três repetições, em esquema de parcelas repetidas no tempo. Nas parcelas empregou-se o esquema fatorial $3 \times 4$, sendo três cultivares de Brachiaria brizantha (MG-4, Marandu e Xaraés) e quatro doses de nitrogênio $\left(0,50,100\right.$ e $\left.150 \mathrm{mg}^{-\mathrm{dm}^{-3}}\right)$.
No tempo foram alocados os três cortes de avaliação, referente às épocas dos cortes. Como fonte de nitrogênio utilizou-se a ureia. O capim-xaraés mostrou maior produtividade, quando comparado aos outros cultivares, sendo considerado mais responsivo à adubação nitrogenada. O efeito mais pronunciado sobre a produção de fitomassa dos cultivares de Brachiaria brizantha e extração dos nutrientes foi proporcionado pelas maiores doses de nitrogênio. A máxima extração de macronutrientes pelos cultivares de Brachiaria brizantha seguiu a ordem decrescente para os macronutrientes $\mathrm{K}$ $>\mathrm{N}>\mathrm{P}>\mathrm{Mg}$. $>\mathrm{S}$ e micronutrientes $\mathrm{Mn}>\mathrm{Fe}>\mathrm{Zn}>\mathrm{Cu}$, sendo necessário repor os nutrientes do solo, com o aumento da adubação nitrogenada.

PALAVRAS-CHAVES: Absorção de nutrientes, Marandu, MG-4, Xaraés.

\section{ABSTRACT}

\section{NUTRIENT EXTRACTION BY PHYTOMASS OF CULTIVARS OF Brachiaria brizantha FITOMASS UNDER NITROGEN DOSES}

Adequate amounts and balanced proportions of nutrient supply is fundamental for the forage productive process. For the fertilization handling, forage plant nutrient requiriment must be known and, consequently, the plant capacity to extract soil nutrients. Therefore, the research had as objective to evaluate the nutrient extraction by Brachiaria brizantha phytomass under nitrogen doses. A randomized complete block experimental design with three replications in a plot repeated in time was used. In the plots, a factorial $3 \times 4$ arrangement was used, being three cultivars of Brachiaria brizantha (MG-4, Marandu and Xaraés) and four nitrogen doses (0, 50, 100 and 150 $\left.\mathrm{mg} \cdot \mathrm{dm}^{-3}\right)$. Three cuts of evaluation were allocated in time, referring. to the time of cuts. The source of nitrogen used was urea. The sharpest treatment effects on phytomass production of Brachiaria brizantha cultivars and nutrient extraction were influenced by the highest nitrogen doses. Xaraés-grass showed greater productivity in relation to the other cultivars, being.considered more responsive to the nitrogen fertilization. The maximum macronutrient extraction by Brachiaria brizantha followed the decreasing.order for the macronutrients: $\mathrm{K}>$ $\mathrm{N}>\mathrm{P}>\mathrm{Mg} .>\mathrm{S}$ and micronutrients: $\mathrm{Mn}>$ Faith $>\mathrm{Zn}>\mathrm{Cu}$, being. necessary to restore soil nutrients, with the increase of nitrogen.

KEYWORDS: Marandu, MG-4, nutrient absorption, Xaraés. 


\section{INTRODUÇÃO}

Com o intuito de atender às exigências dos diferentes sistemas de produção, com variados níveis de tecnologia, a Embrapa Gado de Corte, juntamente com instituições de pesquisa, lançou no mercado alguns cultivares de Brachiaria brizantha. Essas forrageiras foram lançadas visando à sustentabilidade do sistema de produção com alta produtividade dos componentes planta e animal (EMBRAPA, 2007). No entanto, é necessário criar estratégias de manejo da fertilidade do solo, para manter a produtividade e qualidade dessas forrageiras. Dessa forma, o fornecimento de nutrientes em quantidades adequadas e em proporções equilibradas é fundamental no processo produtivo das pastagens.

Para um bom manejo da adubação, torna-se importante conhecer a necessidade de nutrientes das plantas forrageiras e, consequentemente, sua capacidade de extraí-los do solo. Dentre os nutrientes, o nitrogênio e o potássio são os mais extraídos pelas gramíneas forrageiras (BRAZ et al., 2004; PRIMAVESI et al., 2004; CARVALHO et al., 2006; PRIMAVESI et al., 2006; COSTA et al., 2008b). Portanto, estão entre os que mais contribuem para aumentar a produtividade das pastagens.

Diversos trabalhos desenvolvidos com o gênero Brachiaria mostraram elevada responsividade dessas forrageiras a adubações nitrogenadas, no que se refere à produção de massa seca (ALEXANDRINO et al., 2003; BATISTA \& MONTEIRO, 2006; BONFIMDA-SILVA \& MONTEIRO, 2006; CARVALHO et al., 2006; RODRIGUES et al., 2006; RODRIGUES et al., 2008), concentração de macro e micronutrientes (PRIMAVESI et al., 2006; COSTA et al., 2008a) e extração de nutrientes (BRAZ et al., 2004; PRIMAVESI et al., 2006; COSTA et al., 2008b). Esses resultados demonstram que os teores de matéria orgânica disponível no solo são geralmente baixos e não atendem às exigências das forrageiras. Assim, o fornecimento de nitrogênio exerce papel fundamental nas respostas às adubações das pastagens. Entretanto, estudos devem ser realizados com os novos cultivares de Brachiaria brizantha, com o intuito de obter maiores informações nas quantidades aplicadas de nitrogênio e nas quantidades extraídas, com a finalidade de conhecer o comportamento fisiológico e produtivo dessas forra- geiras. Diante disso, objetivou-se avaliar a produção e extração de nutrientes pela fitomassa de cultivares de Brachiaria brizantha sob doses de nitrogênio.

\section{MATERIAL E MÉTODOS}

Desenvolveu-se o experimento em casa de vegetação da Embrapa Arroz e Feijão, em Santo Antônio de Goiás, GO, utilizando-se amostras de um Latossolo Vermelho, de textura argilosa, coletada na camada de 0 a $20 \mathrm{~cm}$. As características químicas do solo no início do experimento foram: $\mathrm{pH}$ em água: 5,$9 ; \mathrm{Ca}: 3,7 \mathrm{cmol}_{\mathrm{c}}$ $\mathrm{dm}^{-3}$; Mg: 1,02 $\mathrm{cmol}_{\mathrm{c}} \cdot \mathrm{dm}^{-3}$; Al: $0,0 \mathrm{cmol}_{\mathrm{c}} \cdot \mathrm{dm}^{-3} ; \mathrm{H}+\mathrm{Al}:$ 3,1 $\mathrm{cmol}_{\mathrm{c}} \cdot \mathrm{dm}^{-3}$; K: $0,28 \mathrm{cmol}_{\mathrm{c}} \cdot \mathrm{dm}^{-3}$; P: $2,8 \mathrm{mg}^{-3} \mathrm{dm}^{-3}$; $\mathrm{SO}_{4}^{-2}: 10,8 \mathrm{mg} \cdot \mathrm{dm}^{-3} ; \mathrm{Cu}: 1,9 \mathrm{mg} \cdot \mathrm{dm}^{-3} ; \mathrm{Zn}: 1,6 \mathrm{mg} \cdot \mathrm{dm}^{-3}$; Fe: 26 mg.dm ${ }^{-3}$; Mn: 47,8 mg.dm ${ }^{-3}$; CTC: $8,1 \mathrm{cmol}_{\text {c }}$. $\mathrm{dm}^{-3}$, V: 61,7 \%; M.O: 18 g. $\mathrm{kg}^{-1}$.

O delineamento experimental utilizado foi blocos completos ao acaso, com três repetições, em esquema de parcelas repetidas no tempo. Nas parcelas empregou-se o esquema fatorial $3 \times 4$, sendo três cultivares de Brachiaria brizantha (MG-4, Marandu e Xaraés) e quatro doses de nitrogênio $(0,50,100$ e $150 \mathrm{mg} \cdot \mathrm{dm}^{-3}$ ). No tempo alocaram-se os três cortes de avaliação, referentes às épocas dos cortes. Como fonte de nitrogênio empregou-se a ureia.

Foram utilizados vasos contendo $10 \mathrm{~kg}$.de terra. Antes da semeadura o solo recebeu a aplicação de 25 mg.dm ${ }^{-3}$ de $\mathrm{P}_{2} \mathrm{O}_{5}$ e $2,5 \mathrm{mg} \cdot \mathrm{dm}^{-3}$ de zinco, utilizando como fontes superfosfato triplo e sulfato de zinco, respectivamente. Realizou-se a semeadura logo após a adubação, sendo colocadas quinze sementes de cada cultivar por vaso. Sete dias após a emergência, iniciaram-se desbastes periódicos, deixando cinco plantas por vaso.

A adubação nitrogenada foi parcelada em três aplicações, sendo a primeira realizada logo após o desbaste das plantas nos vasos, a segunda e a terceira, após o primeiro e segundo corte de avaliação das forrageiras, respectivamente.

Procedeu-se aos cortes de avaliação trinta dias após a adubação nitrogenada, com intervalos de trinta dias entre eles. Cortaram-se as forrageiras a uma altura de $5 \mathrm{~cm}$ do solo. O material coletado foi pesado e seco em estufa com ventilação forçada de ar, com temperaturas entre 58 e $65^{\circ} \mathrm{C}$ por 72 horas, para determinação da matéria seca. Após a secagem, as amostras foram 
moídas em moinho tipo Willey, com peneira de crivo de $1 \mathrm{~mm}$,e armazenadas em sacos de plástico para serem analisadas.

Realizou-se análise química para determinação das concentrações de nitrogênio $(\mathrm{N})$, fósforo $(\mathrm{P})$, potássio $(\mathrm{K})$, cálcio $(\mathrm{Ca})$, magnésio $(\mathrm{Mg})$ e enxofre $(\mathrm{S})$, zinco $(\mathrm{Zn})$, cobre $(\mathrm{Cu})$, manganês $(\mathrm{Mn})$ e ferro $(\mathrm{Fe})$, de acordo com a metodologia descrita por MALAVOLTA et al. (1997).

A extração dos nutrientes foi calculada pela fórmula: nutriente extraído $\left(\mathrm{g} \cdot \mathrm{vaso}^{-1}\right)=0,001 \mathrm{x}$ [massa seca $\left(\right.$ g.vaso $\left.{ }^{-1}\right) \times$ teor do nutriente $\left.\left(\mathrm{g} . \mathrm{kg}^{-1}\right)\right]$, considerando a média correspondente aos três cortes realizados.

Os dados obtidos receberam tratamento estatístico pelo software SISVAR 4,6 (FERREIRA, 2000). Realizou-se análise de variância para as combinações das doses de nitrogênio e cultivares de Brachiaria brizantha. Em função da significância para essas variáveis, ajustaram-se curvas de regressão. Utilizou-se o nível de significância de 5\% em todos os testes estatísticos.

\section{RESULTADOS E DISCUSSÃO}

A análise de variância não mostrou diferenças significativas $(\mathrm{P}>0,05)$ das épocas dos cortes de avaliação em todas as variáveis estudadas, mostrando significância apenas para as doses e cultivares de Brachiaria brizantha.

As produções de massa seca dos cultivares estudado foram influenciadas pelas doses de nitrogênio. Observou-se aumento linear na produção de massa seca, em todos os cultivares de Brachiaria brizantha, com o aumento das doses de nitrogênio (Figura 1). Os valores médios de produção, na dose máxima estudada, foram de 35,4; 36,8 e 39,9 g.vaso ${ }^{-1}$, mostrando aumento de $26 ; 28$ e $31 \%$ em relação à não aplicação de nitrogênio nos cultivares MG-4, Marandu e Xaraés, respectivamente. Esses resultados apontam para a necessidade da adubação nitrogenada para maiores produções, uma vez que o tratamento-controle (testemunha) apresentou baixa produtividade em relação às doses de nitrogênio estudadas. A adubação nitrogenada é uma estratégia que permite aumentar a densidade volumétrica de forragem e, sobretudo, a produção de folhas no perfil da pastagem, devido ao aparecimento e alongamento de folhas, aumentando, assim, a produção de massa seca.
YDOYAGA et al. (2006), trabalhando com métodos de recuperação de pastagens de Brachiaria decumbens, verificaram que a adubação nitrogenada propiciou aumento de $34 \%$ na produção de massa seca na dose máxima estudada (100 kg.ha-1). Em estudos com doses de nitrogênio e enxofre em pastagem degradada de capim-braquiária, BONFIM-DA-SILVA \& MONTEIRO (2006) verificaram que as doses de nitrogênio estudadas foram determinantes para a produção de massa seca das lâminas foliares e dos colmos mais bainhas. Resultados positivos de adubação nitrogenada no capim-marandu também foram obtidos por ALEXANDRINO et al. (2005) e PRIMAVESI et al. (2006).

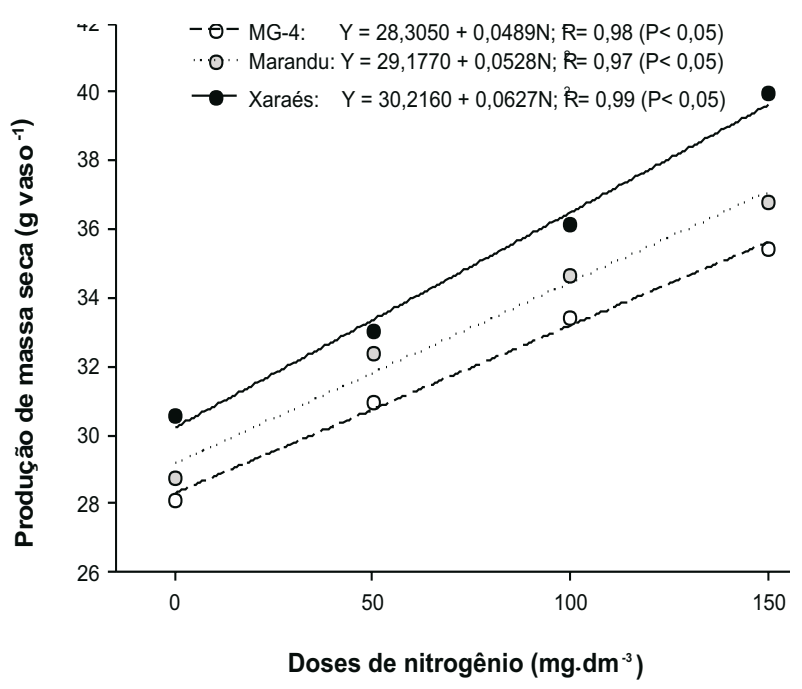

FIGURA 1. Produção de massa seca (a) e teores de proteína bruta (b) na matéria seca (MS) de cultivares de Brachiaria brizantha sob doses de nitrogênio.

O capim-xaraés apresentou maior produtividade em relação aos outros cultivares, com aumento na dose máxima de $13 \%$ e $9 \%$ em relação aos capins MG-4 e marandu, respectivamente. Isso pode ser explicado por duas razões. A primeira refere-se à alta responsividade do capim-xaraés à adubação nitrogenada (RODRIGUES et al., 2008). A segunda seria decorrente da morfologia desse cultivar, que apresenta lâmina foliar mais larga $(2,5 \mathrm{~cm})$ e mais comprida $(60 \mathrm{~cm})$ do que os outros cultivares de Brachiaria brizantha (VILELA, 2007). FLORES et al. (2008) relataram que o 
capim-xaraés possui vantagens em relação aos outros cultivares de Brachiaria, como maior velocidade de rebrota e maior produção de forragem, o que garante mais alta capacidade de suporte e maior produtividade por área. RODRIGUES et al. (2008) observaram que a adubação nitrogenada exerceu efeito positivo na produção de massa seca total do capim-xaraés.

A interação doses de nitrogênio e cultivares de Brachiaria brizantha não influenciou nas extrações foliares de nutrientes. Houve efeito significativo da extração apenas das doses de nitrogênio, independente dos cultivares estudados. À exceção da extração de cálcio, todos os nutrientes avaliados foram influenciados $(\mathrm{P}<0,05)$ pelas doses de nitrogênio.

Houve aumento linear na extração de nitrogênio, com o incremento das doses de nitrogênio (Figura 2). A média ajustada na dose máxima foi de 0,6930 g.vaso ${ }^{-1}$, mostrando aumento de $70 \%$, em relação à não aplicação de nitrogênio. Essa grande extração na dose máxima pode ser explicada pelo aumento de produção de massa seca nessa dose, em que a planta exigiu uma quantidade maior de nutrientes para obter sua produção. MALAVOLTA et al. (1997) relataram que o nitrogênio participa de diversos processos na planta, dentre eles a divisão celular e a constituição de tecidos. Assim, o aumento na produção de MS obtida pelo incremento do fornecimento de nitrogênio, dentro de certos limites, deve-se às várias funções que desempenha na planta, como componentes estruturais de proteínas e enzimas (TAIZ \& ZEIGER, 2004).

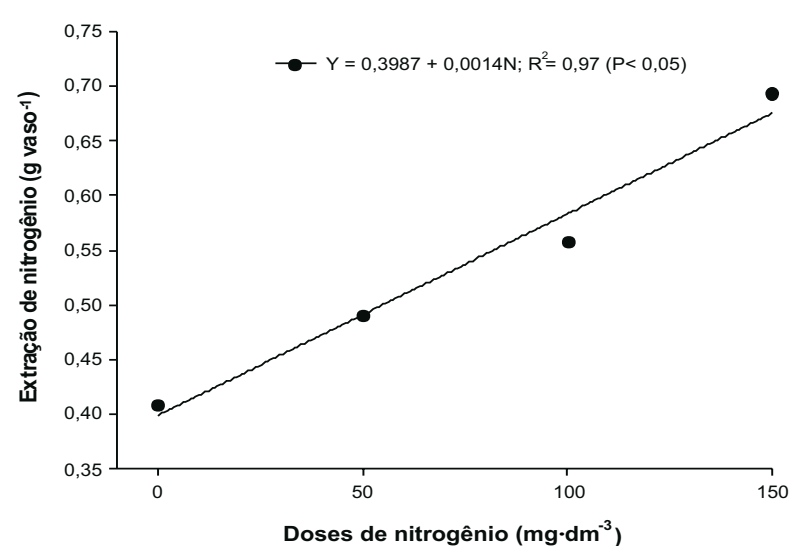

FIGURA 2. Extração de nitrogênio na fitomassa de cultivares de Brachiaria brizantha sob doses de nitrogênio (médias de três cortes).
A extração de fósforo pelos cultivares de Brachiaria brizantha apresentou resposta linear em função das doses de nitrogênio aplicadas (Figura 3). A maior dose de nitrogênio foi responsável por extrair $48 \%$ do fósforo no tecido foliar. Esse incremento da extração de fósforo deve-se, portanto, ao aumento da produção de MS, em que as forrageiras exigiram maiores quantidades de fósforo para aumentar a produtividade. Em estudo de doses de nitrogênio na extração de nutrientes pelo capim-coastcross, PRIMAVESI et al. (2004) verificaram maior extração de fósforo, com o aumento das doses de nitrogênio. Resultados semelhantes também foram obtidos por COSTA et al. (2008) no capim-xaraés.

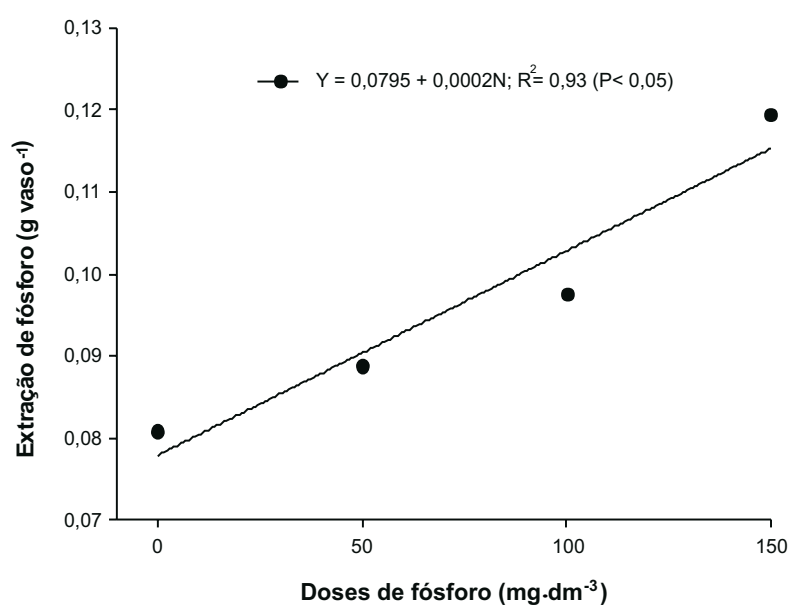

FIGURA 3. Extração de fósforo na fitomassa de cultivares de Brachiaria brizantha sob doses de nitrogênio (médias de três cortes).

Assim como para o fósforo e nitrogênio, a extração de potássio apresentou ajuste linear com o aumento das doses de nitrogênio (Figura 4). A média ajustada na dose máxima foi de 0,8321 g.vaso ${ }^{-1}$, mostrando aumento de 36\% em relação à não aplicação de nitrogênio. A extração de potássio foi superior à extração de nitrogênio. Trata-se de resultados que indicam que as cultivares de Brachiaria brizantha extraem muito potássio do solo.

PRIMAVESI et al. (2006), trabalhando com extração de nutrientes na fitomassa de capim-marandu em função de fontes e doses de nitrogênio, verificaram extração bem maior de potássio em relação ao nitrogênio, mesmo no tratamento sem nitrogênio, mas que recebeu 
potássio. Entretanto, PRIMAVESI et al. (2004) verificaram extrações semelhantes de potássio e nitrogênio no capim-coastcross submetidas a doses de nitrogênio.

As doses de nitrogênio não foram influenciadas $(\mathrm{P}>0,05)$ pela extração de cálcio. Contudo, observa-se, na Figura 5, aumento linear da extração de magnésio, com aumento das doses de nitrogênio, mostrando aumento na dose máxima de $10,9 \%$ em relação à não aplicação de nitrogênio. O baixo incremento da extração de magnésio na dose máxima de nitrogênio pode ter sido resultado da inibição competitiva do potássio no processo de absorção com o magnésio (MARSCHNER, 1995), em virtude da grande quantidade de potássio armazenada no solo.

A extração de enxofre pelas cultivares de $\mathrm{Bra}$ chiaria brizantha apresentou aumento quadrático em relação às doses de nitrogênio aplicadas (Figura 6). A média ajustada na dose máxima foi de 0,0610 g.vaso ${ }^{-1}$, mostrando aumento de $91 \%$ em relação à não aplicação de nitrogênio. Em virtude das funções desempenhadas pelo nitrogênio e enxofre como componentes estruturais de proteínas e enzimas, justifica-se a resposta obtida para a extração de enxofre em função das doses de nitrogênio (EPSTEIN \& BLOOM, 2006). Em trabalho realizado em solução nutritiva, com o capim-marandu, BATISTA \& MONTEIRO (2006) observaram aumentos marcantes na extração de enxofre pelas plantas com o aumento da concentração de nitrogênio no meio de cultivo.

Observa-se, na Figura 7, aumento linear na extração de zinco com o acréscimo das doses de nitro- gênio. A maior extração foi de 0,6717 g.vaso ${ }^{-1}$ na dose máxima, mostrando aumento de $20 \%$ em relação à não aplicação de nitrogênio. Resultados semelhantes foram obtidos por PRIMAVESI et al. (2004) e PRIMAVESI et al. (2006), que observaram maiores extrações de zinco com aumento das doses de nitrogênio.

O mesmo comportamento da extração de zinco foi observado na extração de cobre, com aumento linear em relação às doses de nitrogênio aplicadas. A média ajustada na dose máxima foi de 0,1608 g.vaso ${ }^{-1}$ com aumento de $12 \%$, em relação à não aplicação de nitrogênio. Em estudo avaliando a quantidade de nutriente extraído nas folhas de milheto e dos capins braquiária e mombaça, BRAZ et al. (2004) observaram que a menor extração de micronutrientes foi do cobre e a maior de ferro, resultados esses similares aos observados neste estudo.

A extração de manganês também foi influenciada pelas doses de nitrogênio, mostrando aumento com acréscimo das doses de nitrogênio (Figura 9). Obtevese a maior extração de manganês $\left(5,1811\right.$ g.vaso $\left.{ }^{-1}\right)$ na dose máxima de nitrogênio, com aumento de $15 \%$, em relação à não aplicação desse nutriente.

Observa-se, na Figura 10, que o incremento das doses de nitrogênio aumenta a extração de ferro. A média ajustada na dose máxima foi de 4,6034 g.vaso ${ }^{-1}$, mostrando aumento de $28 \%$, em relação à não aplicação de nitrogênio. Aumentos na extração de ferro também foram obtidos por PRIMAVESI et al. (2004) e PRIMAVESI et al. (2006), com aumento nas doses de nitrogênio.

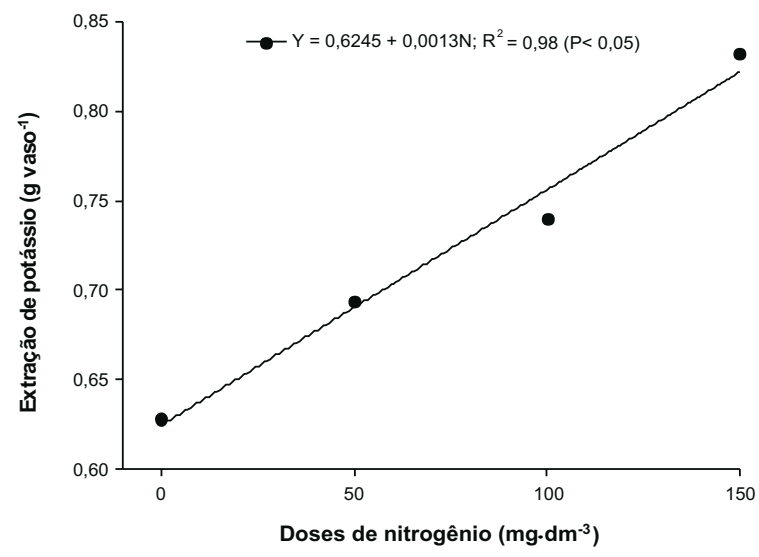

FIGURA 4. Extração de potássio na fitomassa de cultivares de Brachiaria brizantha sob doses de nitrogênio (médias de três cortes).

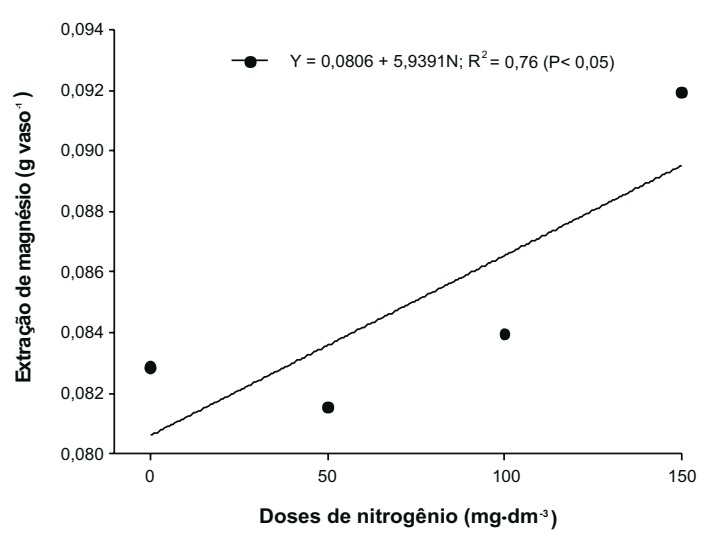

FIGURA 5. Extração de magnésio na fitomassa de cultivares de Brachiaria brizantha sob doses de nitrogênio (médias de três cortes). 


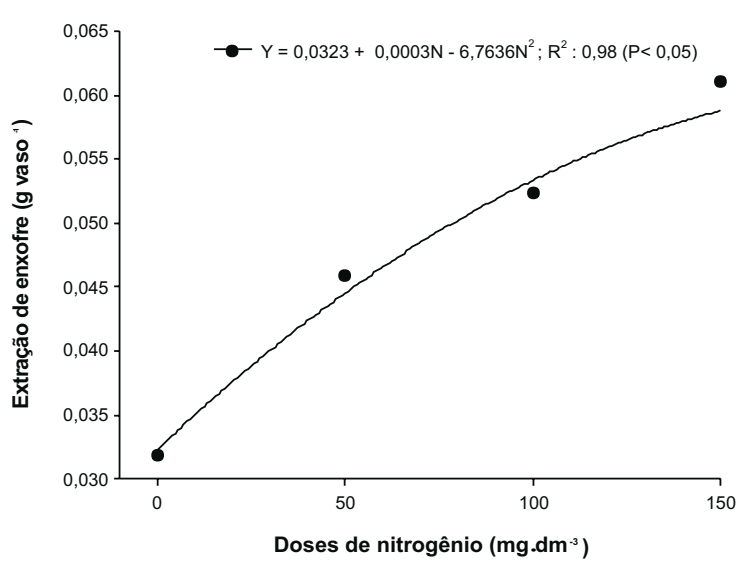

FIGURA 6. Extração de enxofre na fitomassa de cultivares de Brachiaria brizantha sob doses de nitrogênio (médias de três cortes).

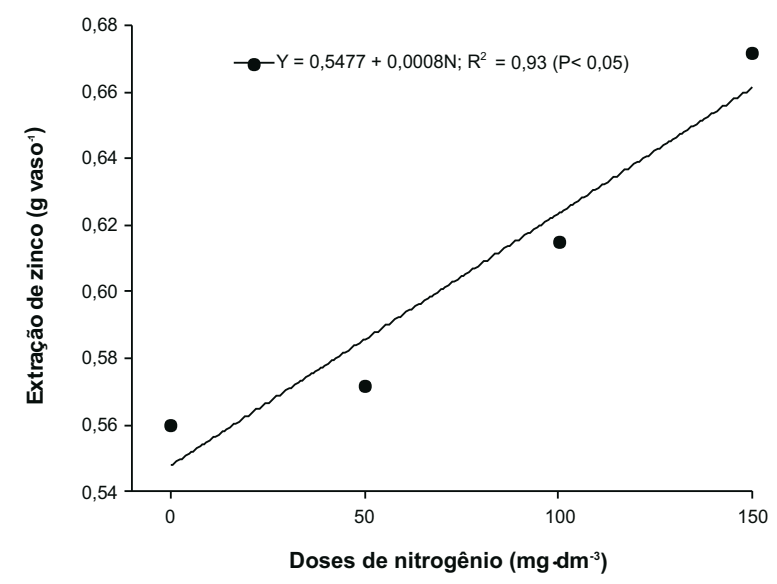

FIGURA 7. Extração de zinco na fitomassa de cultivares de Brachiaria brizantha sob doses de nitrogênio (médias de três cortes).

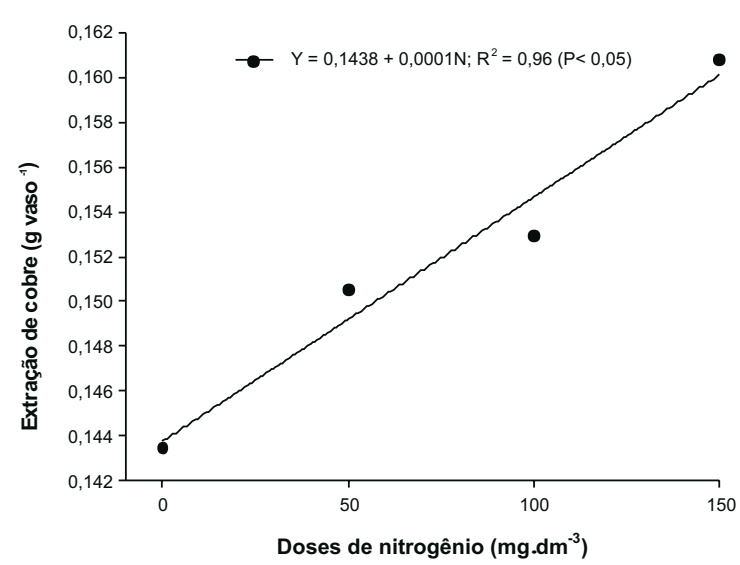

FIGURA8. Extração de cobre na fitomassa de cultivares de Brachiaria brizantha sob doses de nitrogênio (médias de três cortes).

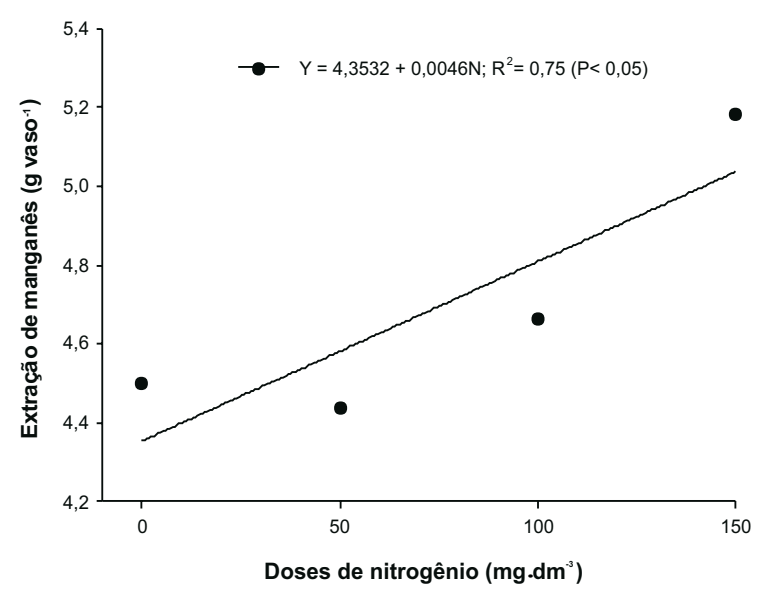

FIGURA 9. Extração de manganês na fitomassa de cultivares de Brachiaria brizantha sob doses de nitrogênio (médias de três cortes).

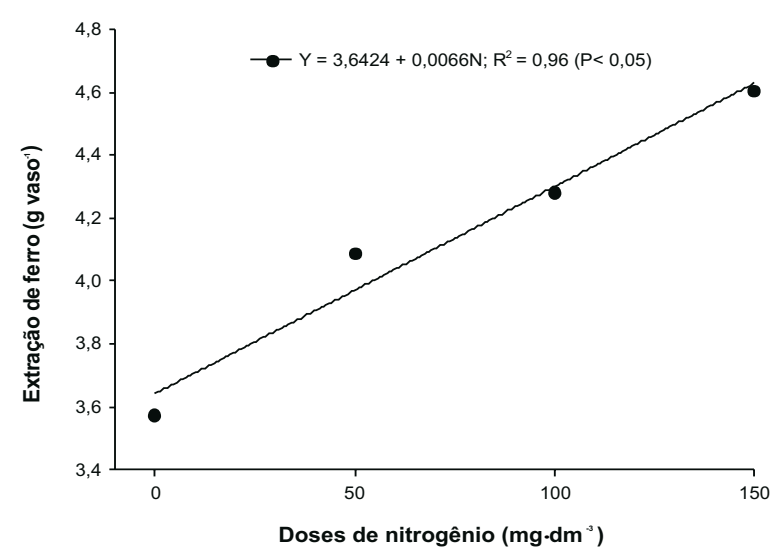

FIGURA 10. Extração de ferro na fitomassa de cultivares de Brachiaria brizantha sob doses de nitrogênio (médias de três cortes).

As extrações dos macronutrientes foram maiores para potássio e nitrogênio, seguidas de fósforo, magnésio e enxofre, semelhantes às extrações obtidas por PRIMAVESI et al. (2004), CARVALHO et al. (2006), PRIMAVESI et al. (2006) e COSTA et al. (2008), e dos micronutrientes foram maiores para manganês, ferro, zinco e cobre, similares às extrações obtidas por BRAZ et al. (2004). Esses resultados demonstram que, para manter a produtividades dessas forrageiras, é necessário repor os nutrientes que são extraídos do solo, por causa do aumento da fitomassa, para obter respostas mais significativas em relação à eficiência da adubação nitrogenada. 


\section{CONCLUSÕES}

O capim-xaraés mostrou maior produtividade quando comparado aos outros cultivares, sendo considerado mais responsivo à adubação nitrogenada. $\mathrm{O}$ efeito mais pronunciado sobre a produção de fitomassa dos cultivares de Brachiaria brizantha e extração dos nutrientes foi proporcionado pelas maiores doses de nitrogênio.

A máxima extração de macronutrientes pelos cultivares de Brachiaria brizantha seguiu a ordem decrescente para os macronutrientes $\mathrm{K}>\mathrm{N}>\mathrm{P}>$ $\mathrm{Mg}$. $>\mathrm{S}$ e micronutrientes $\mathrm{Mn}>\mathrm{Fe}>\mathrm{Zn}>\mathrm{Cu}$, sendo necessário repor os nutrientes do solo, com o aumento da adubação nitrogenada.

\section{REFERÊNCIAS}

ALEXANDRINO, E.; NASCIMENTO JÚNIOR, D.; REGAZZI, A. J.; MOSQUIM, P. R.; ROCHA, F. C.; SOUSA, D. P. Produção de massa seca e vigor de rebrotação de Brachiaria brizantha cv. Marandu submetida a diferentes doses de nitrogênio e frequência de cortes. Brazilian Journal of Veterinary Research and Animal Science, v. 40, n. 2, p. 141-147, 2003.

ALEXANDRINO, E.; NASCIMENTO JÚNIOR, D.; REGAZZI, A. J.; MOSQUIM, P. R.; ROCHA, F. C.; SOUZA, D. P. Características morfogênicas e estruturais da Brachiaria brizantha cv. Marandu submetida a diferentes doses de nitrogênio e frequências de cortes. Acta Scientiarum Agronomy, v. 27, n. 1, p. 17-24, 2005.

BATISTA, K.; MONTEIRO, F. A. Respostas morfológicas e produtivas do capim-Marandu adubado com doses combinadas de nitrogênio e enxofre. Revista Brasileira de Zootecnia, v. 35, n. 4, p. 1281-1288, 2006.

BONFIM-DA-SILVA, E. M.; MONTEIRO, F. A. Nitrogênio e enxofre em características produtivas do capim-braquiária proveniente de área de pastagem em degradação. Revista Brasileira de Zootecnia, v. 35, n. 4, p. 1289-1297, 2006.

BRAZ, A. J. B. P.; SILVEIRA, P. M.; KLIEMANN, H. J.; ZIMMERMANN, F. J. P. Acumulação de nutrientes em folhas de milheto e dos capins braquiária e mombaça. Pesquisa Agropecuária Tropical, v. 34, p. 83-87, 2004.

CARVALHO, F. G. BURITY, H. A.; SILVA, V. N.; SILVA, L. E. S. F.; SILVA, A. J. N. Produção de matéria seca e concentração de macronutrientes em Brachiaria decumbens sob diferentes sistemas de manejo na zona da mata de Pernambuco. Pesquisa Agropecuária Tropical, v. 36, p. 101-106, 2006.
COSTA, K. A. P; ARAUJO, J. L.; FAQUIN, V.; OLIVEIRA, I. P.; FIGUEIREDO, F. C.; GOMESI, K. W. Extração de macronutrientes pela fitomassa do capim-xaraés em função de doses de nitrogênio e potássio. Ciência Rural, v. 38, n. 4, p. 1162-1166, 2008 a.

COSTA, K. A. P; OLIVEIRA, I. P.; FAQUIN, V.; FIGUEIREDO, F. C.; RODRIGUES, C. R.; NASCIMENTO, P. P. Adubação nitrogenada e potássica na concentração de nutrientes do capim-xaraés. Ciência Animal Brasileira, v. 9, n. 1, p. 86-92, 2008 b.

EMBRAPA GADO DE CORTE. Capim-xaraés. Disponível em: $<$ http://www.cnpgc.embrapa.br/produtoseservicos/xaraes.html $>$. Acesso em: 22 nov. 2009.

EMPRESA BRASILEIRA DE PESQUISA AGROPECUÁRIA. Centro Nacional de Pesquisa de Solos. Ministério da Agricultura e do Abastecimento. Manual de métodos de análise de solo. 2. ed. rever. e atual. Rio de Janeiro: Embrapa CNPS, 1997. 212 p.

EPSTEIN, E.; BLOOM, A. Nutrição mineral de plantas: princípios e perspectivas. Londrina: Editora Planta, 2006. 169 p.

FERREIRA, D. F. Análises estatísticas por meio do Sisvar para Windows versão 4.0. In: REUNIÃO ANUAL DA REGIÃO BRASILEIRA DA SOCIEDADE INTERNACIONAL DE BIOMETRIA, 2000, São Carlos, SP. Anais... São Carlos, SP: UFSCar, 2000. p. 255-258, 2000.

FLORES, R. S.; EUCLIDES, V. P. B.; ABRÃO, M. P. C.; GALBEIRO, S.; DIFANTE, G. S.; BARBOSA, R. A. Desempenho animal, produção de forragem e características estruturais dos capins marandu e xaraés submetidos a intensidades de pastejo. Revista Brasileira de Zootecnia, Viçosa, v. 37, n. 8, p. 13551365, 2008.

MALAVOlTA, E.; VITTI, G. C.; OLIVEIRA, S. A. Avaliação do estado nutricional das plantas: princípios e aplicações. 2. ed. Piracicaba: Associação Brasileira da Potassa e do Fosfato, 1997. $319 \mathrm{p}$.

MARSCHNER, H. Mineral nutrition of higher plants. 2. ed. London: Academic Press, 1995. 889 p.

PRIMAVESI, A. C.; PRIMAVESI, O.; CORREAA, L. A.; CANTARELLA, H.; SILVA, A. G.; FREITAS, A. R; VIVALDI, L. F. Adubação nitrogenada em Capim-Coastcross: efeitos na extração de nutrientes e recuperação aparente do nitrogênio. Revista Brasileira de Zootecnia, v. 33, n. 1, p. 68-78, 2004.

PRIMAVESI, A. C.; PRIMAVESI, O.; CORRÊA, L. A.; SILVA, A. G.; CANTARELLA, H. Nutrientes na fitomassa de capim-marandu em função de fontes e doses de nitrogênio. Ciência e Agrotecnologia, Lavras, v. 30, n. 3, p. 562-568, 2006. 
RODRIGUES, R. C.; ALVES, A. C; BRENNECKE, K.; PLESE, L. P. M.; LUZ, P. H. C. Densidade populacional de perfilhos, produção de massa seca e área foliar do capim-xaraés cultivado sob doses de nitrogênio e potássio. Boletim Indústria Animal, v. 63, n. 1, p. 27-33, 2006.

RODRIGUES, R. C.; MOURÃO, G. B.; BRENNECKE, K.; LUZ, P. H. C; HERLING, V. R. Produção de massa seca, relação folha/ colmo e alguns índices de crescimento do Brachiaria brizantha cv. Xaraés cultivado com a combinação de doses de nitrogênio e potássio. Revista Brasileira de Zootecnia, v. 37, n. 3, p. 394400, 2008.

SOUZA, F. H. D. As sementes de espécies forrageiras do gênero Brachiaria no Brasil Central: a Brachiaria no novo século. 2. ed. Nova Odessa: Instituto de Zootecnia, 2002.
TAIZ, L.; ZEIGER, E. Fisiologia vegetal. Porto Alegre: Artmed, 2004. p. 449-484.

VILELA, H. Séries gramíneas tropicais: gênero Brachiaria (Brachiaria brizantha cv. MG5,Vitória. Disponível em: <http://www. agronomia.com.br/conteudo/artigos/artigos_gramineas_tropicais_brachiaria.htm.> Acesso em: 5 out. 2007.

YDOYAGA, D. F.; LIRA, M. A.; SANTOS, M. V. F.; DUBEUX JÚNIOR, J. C. B.; SILVA, M. C.; SANTOS, V. F.; FERNANDES, A. P. M. Métodos de recuperação de pastagens de Brachiaria decumbens Stapf. no agreste pernambucano. Revista Brasileira de Zootecnia, v. 35, n. 3, p. 699-705, 2006.

Protocolado em: 9 jun. 2008. Aceito em: 12 fev. 2010. 